\title{
Strength and Speed Comparison in Youth Soccer Players in One Year of Trainning
}

\author{
Kuriu, A. \\ Jarani, J. \\ Spahiu, M.
}

Sports University of Tirana, Albania, Corresponding author; Abdyl Kuriu, Sports University of Tirana, Tirana, Albania

Email: ustinfostudent@gmail.com

\section{Doi:10.5901/mjss.2015.v6n4s1p354}

\section{Abstract}

Introduction. The aim of this study was to evaluate and compare the speed and strength during one year in youth soccer players in two time measurement. Methods. In this study participated 250 youth soccer players. The mean age of participant was 17.6 ( \pm 1.6$)$ years. All youth members were engaged in formal training (3-4 sessions/week; 90-120 min/ sessions) and had competed for at least 3 years. The youth were assessed for speed $(50 \mathrm{~m})$ and strength for the lower limbs (standing broad jump) during one year in two time measurement (year 2013- T1 and year 2014- T2). Results. ANOVA test for comparison for T1 and T2 measurement show a significant improvement of the performance for running speed by 0.15 second ( $F=46.1 ; P$ value $=0.00)$ and standing broad jump by $0.12 \mathrm{~m}(F=37.2 ; P$ value $=0.00)$. Conclusion. In conclusion, the results show that the players improved significant the results for speed and strength for the lower limbs. This component play an important role in achieving better results in soccer games in youth.

Keywords: speed, youth, strength, physical performance

\section{Introduction}

Research for years have indicated the role that aerobic fitness plays on soccer game and its positive effects (Apor, 1988; Wisloff et al., 1988). In the study by Helgerud et al., (2001) show that the soccer performance for technical performance and tactical aspects is affected by maximum oxygen uptake (VO2max) and running economy, by about $5 \mathrm{ml} / \mathrm{kg} / \mathrm{min}$ and $7 \%$, respectively improvements. It is difficult to find the right normative data for the sprint, strength and vertical jump in youth soccer players as it differ from ages, soccer teams and competition and more is shown in izokinetic and izometric muscle strength (Cometti et al., 2001; Capranica et al., 1992). Results from a study of Rely et al., (2000) show that physical parameters like speed, power and strength are important components in reaching good performance in jumping, kicking and sprinting in soccer players during the game. regarding strength data show that muscle weakness is associated with injury in lower extremities with focus on hamstring muscles (Orchard et al., 1997) and in contrary muscle strength of lower limbs is associated with good performance in sprint and vertical jump height (Wisloff et al., 2004). Coaches have to be aware of the physical performance results of their teams member in order to have a better planning for the entire year of coaching. The aim of this study was to evaluate and compare the speed and strength during one year in youth soccer players in two time measurement.

\section{Methods}

\subsection{Participants}

Two hundred and fifty young soccer players participated in the study and were selected from four teams. These teams were selected randomly from a pool of twelve teams that participate regularly in youth Albanian soccer national championship. All participants were informed of the purpose of the study and gave their informed consent to participate. The mean age of all youth soccer players was $17.6( \pm 1.6)$ years. All youth members were engaged in formal training (3-4 sessions/week; $90-120 \mathrm{~min} /$ sessions) and had competed for at least 3 years. The youth were assessed for speed (50m) and strength for the lower limbs (standing broad jump) during one year in two time measurement (year 2013- T1 and year 2014- T2) 


\subsection{Protocols of the tests}

Standing broad jump (Eurofit., 1993) to measure the explosive power of the lower limbs.

The performer stands behind a line marked on the ground with feet slightly apart. A two foot take-off and landing is used, with swinging of the arms and bending of the knees to provide forward drive. The performer attempts to jump as far as possible, landing on both feet without falling backwards. Three attempts are allowed. The measurement is taken from take-off line to the nearest point of contact on the landing (back of the heels). Record the longest distance jumped, the best of three attempts. For this test equipment are required: tape measure to measure distance jumped, non-slip floor for takeoff, and soft landing area preferred. The take off line should be clearly marked

Speed $50 \mathrm{~m}$ ahead. The aim of this test is to assess the speed. Marker cones and/or lines are placed fifty meters apart. The performer starts with a foot at one marker. When instructed by the timer, the performer runs to the opposite marker $50 \mathrm{~m}$ ahead covering 50 meters in total.

The time taken to complete 50 meters course is recorded (seconds). For this test equipment are required: stopwatch, marker cones, and a flat non-slip surface.

\section{Statistical Analysis}

It was creating a specific data base in excel file (time one during year 2013 and time second during year 2014 test results) and then converted in SPSS database. Descriptive statistics (mean and standard deviations) for T1 and T2 were calculated for the variables assessed in this study. Differences were determined with a single ANOVA test followed by LSD post hoc test. All variables assessed in this study were tested for normality. A significant level of $p<0.05$ was accepted. All analysis was performed using the statistics software SPSS 17.0

\section{Results}

Data on table 1 show the number for participant in this study. There were four teams that were randomly selected in this study. During the first year 250 youth soccer players participated during the first time measurement and 246 youth participated in the second time measurement during 2014 year. Only four players missed on second measurement for the injuries that they have during performance of the tests.

Table 1. Number of participants by team, measurement and mean age

\begin{tabular}{|c|c|c|c|c|}
\hline Team & Measurement & $\mathrm{N}$ & Mean Age & $\mathrm{sd}$ \\
\hline \multirow[t]{2}{*}{ Team 1} & T1 & 57 & 17.6 & 1.9 \\
\hline & T2 & 57 & & \\
\hline \multirow[t]{2}{*}{ Team 2} & T1 & 55 & 17.9 & 1.4 \\
\hline & $\mathrm{T} 2$ & 54 & & \\
\hline \multirow[t]{2}{*}{ Team 3} & T1 & 68 & 17.6 & 1.6 \\
\hline & $\mathrm{T} 2$ & 66 & & \\
\hline \multirow[t]{2}{*}{ Team 4} & $\mathrm{~T} 1$ & 70 & 17.4 & 1.6 \\
\hline & T2 & 69 & & \\
\hline
\end{tabular}

Note: T1- first measurement 2013 year; T2- second measurement 2014 year

Descriptive statistics are shown in table 2 for speed by teams and time measurement. Mean results for team one for speed, were for T1 measurement $6.92 \mathrm{~s}$ (sd 0.18) and for T2 measurement $6.69 \mathrm{~s}$ (sd 0.20); team 2 on T1 was $6.90 \mathrm{~s}$ (sd 0.31 ) and on T2 was $6.72 \mathrm{~s}$ (sd 0.30); team 3 on T1 was $6.62 \mathrm{~s}$ (sd 0.19) and on T2 was $6.55 \mathrm{~s}$ (sd 0.20); team 4 on T1 was $6.81 \mathrm{~s}(\mathrm{sd} 0.21)$ and on $\mathrm{T} 2$ was $6.63 \mathrm{~s}(\mathrm{sd} \mathrm{0.30).}$ 
Table 2. Descriptive statistics for speed for time 1 and time 2 measurement by team

\begin{tabular}{cccccc}
\hline Team & Measurement & Variable & N & Mean & sd \\
\hline Team 1 & T1 & Speed 50m (s) & 57 & 6.92 & 0.18 \\
& T2 & Speed 50m (s) & 57 & 6.69 & 0.20 \\
Team 2 & T1 & Speed 50m (s) & 55 & 6.90 & 0.31 \\
& T2 & Speed 50m (s) & 54 & 6.72 & 0.30 \\
Team 3 & T1 & Speed 50m (s) & 68 & 6.62 & 0.19 \\
& T2 & Speed 50m (s) & 66 & 6.55 & 0.20 \\
Team 4 & T1 & Speed 50m (s) & 70 & 6.81 & 0.21 \\
& T2 & Speed 50m (s) & 69 & 6.63 & 0.28 \\
\hline \hline
\end{tabular}

Descriptive statistics are shown in table 3 for explosive power for lower limbs measurement by standing broad jump test by teams and time measurement. Mean results for team one for standing broad jump, were for T1 measurement $2.28 \mathrm{~m}$ (sd 0.23) and for T2 measurement $2.40 \mathrm{~m}$ (sd 0.16); team 2 on T1 was $2.19 \mathrm{~m}$ (sd 0.14) and on T2 was $2.32 \mathrm{~m}$ (sd 0.11); team 3 on T1 was $2.26 \mathrm{~m}$ (sd 0.07) and on T2 was $2.37 \mathrm{~m}$ (sd 0.27); team 4 on T1 was $2.28 \mathrm{~m}$ (sd 0.28) and on T2 was $2.40 \mathrm{~m}$ (sd 0.29).

Table 3. Descriptive statistics for explosive power for lower limb for time 1 and time 2 measurement by team

\begin{tabular}{cclccc}
\hline Team & Measurement & Variable & N & Mean & sd \\
\hline Team 1 & T1 & Standing broad jump $(\mathrm{m})$ & 57 & 2.28 & 0.23 \\
& T2 & Standing broad jump $(\mathrm{m})$ & 57 & 2.40 & 0.16 \\
Team 2 & T1 & Standing broad jump (m) & 55 & 2.19 & 0.14 \\
& T2 & Standing broad jump (m) & 54 & 2.32 & 0.11 \\
Team 3 & T1 & Standing broad jump (m) & 68 & 2.26 & 0.07 \\
& T2 & Standing broad jump (m) & 66 & 2.37 & 0.27 \\
Team 4 & T1 & Standing broad jump (m) & 70 & 2.28 & 0.28 \\
& T2 & Standing broad jump (m) & 69 & 2.40 & 0.29 \\
\hline \hline
\end{tabular}

Table 4 show the results for descriptive statistics for speed and standing broad jump for entire group participated in this study for T1 and T2 measurement. The performance for speed (T1- 6.8s and T2- 6.65s) and for standing broad jump (T1$2.25 \mathrm{~m}$ and $\mathrm{T} 2-2.37 \mathrm{~m})$.

Table 4. Descriptive statistics for the entire group by time measurement

\begin{tabular}{ccccc}
\hline Measurement & Variables & N & Mean & sd \\
\hline T1 & Speed 50m (s) & 250 & 6.80 & 0.25 \\
& Standing broad jump (m) & 250 & 2.25 & 0.20 \\
T2 & Speed 50m (s) & 246 & 6.65 & 0.26 \\
& Standing broad jump (m) & 246 & 2.37 & 0.23 \\
\hline \hline
\end{tabular}

There is a significant difference about comparison for both variables assessed in this study on T1 and T2 (table 5). ANOVA test for comparison for T1 and T2 measurement show a significant improvement of the performance for running speed by 0.15 second $(F=46.1 ; P$ value $=0.00)$ and standing broad jump by $0.12 \mathrm{~m}(F=37.2 ; P$ value $=0.00)$.

Table 5. ANOVA Test for group (comparison by time measurement)

\begin{tabular}{llccccc}
\hline & & Sum of Squares & df & Mean Square & F & Sig. \\
\hline Speed 50m (s) & Between Groups & 2.984 & 1 & 2.984 & 46.056 & 0.00 \\
& Within Groups & 31.485 & 496 & 0.065 & & \\
& Total & 34.469 & 497 & & & \\
\hline Standing broad jump (m) & Between Groups & 1.68 & 1 & 1.68 & 37.148 & 0.00 \\
& Within Groups & 21.982 & 496 & 0.045 & & \\
& Total & 23.662 & 497 & & & \\
\hline \hline
\end{tabular}




\section{Discussion}

The results on this study showed that in one year of training youth soccer players have improved their physical performance for speed and explosive power for the lower limbs as follows; running speed by 0.15 second ( $F=46.1 ; \mathrm{P}$ value $=0.00)$ and standing broad jump by $0.12 \mathrm{~m}(\mathrm{~F}=37.2 ; \mathrm{P}$ value $=0.00)$.

Results from a study by Reilly et al., (2000) showed that muscle strength for soccer players might be different regarding their competition levels. Researchers in this study have used two measurement for strength; squat test and drop jump test. The results showed significant difference in strength by competition levels as follows; elite, sub elite and recreational teams as regarding strength and coordination. Comparing this result with our study, we conclude that the participators in this study are youth soccer players that attend regularly Albanian national soccer championship. In our study we found that both variables were improved in one year regarding strength and speed. Results from Bencke et al., (2002) and Bobbert et al., (1987) show that jump performance is affected by many factors as the force developed by the knee extensor muscles and intramuscular coordination and co activation of the agonist-antagonist muscles.

Results from a study of Rely et al., (2000) show that physical parameters like speed, power and strength are important components in reaching good performance in jumping, kicking and sprinting in soccer players during the game. regarding strength data show that muscle weakness is associated with injury in lower extremities with focus on hamstring muscles (Orchard et al., 1997)

The findings of our study are so important in the planning of the training for the coaches with regards to physical parameters. The strength and speed assessment may provide useful information achieving higher results. Further research is needed regarding the performance for other abilities like cardiorspiratory fitness, anaerobic performance and combination with technique abilities in soccer. In conclusion, the results show that the players improved significant the results for speed and strength for the lower limbs. This component play an important role in achieving better results in soccer games in youth.

\section{References}

Apor P (1988). Successful formula for fitness training. In: Reilly T, Less A, Davids K, Murphy WJ, eds. Science and football. London: E \& FN Spon,95-107.

Bencke J, Damsgaard R, Sackmose A, Jorgensen P, Jorgensen K, Klausen K (2002) Anaerobic power and muscle strength characteristics of 11 year old elite and non-elite boys and girls from gymnastics, team handball, and swimming. Scandinavian Journal of Medicine and Science in Sports 12: 171-178.

Bobbert I, Huijing P, van Ingen Schenau G (1987) Drop Jumping II. The influence of dropping height on the biomechanics of drop jumping. Medicine and Science in Sports and Exercise 19: 339-346.

Capranica L, Cama G, Fanton F, Tessitore A, Figura F (1992) Force and power of referred and non-preferred leg in young soccer players. Journal Sports Medicine Physical Fitness 32: 358-363.

Cometti G, Maffiuletti NA, Pousson M, Chatard JC, Maffulli N (2001) Isokinetic strength and anaerobic power of elite, subelite and amateur French soccer players. International Journal of Sports Medicine 22: 45-51.

Helgerud J, Engen LC, Wisløff U, et al (2001). Aerobic endurance training improves soccer performance. Med Sci Sports Exerc;33:1925-31.

Eurofit. (1993). Eurofit Tests of Physical Fitness.Strasbourg, 2nd Edition

Orchard J, Marsden J, Lord S, Garlick D (1997) Preseason hamstring muscle weakness associated with hamstring muscle injury in Australian footballers. American Journal of Sports Medicine 25: 81-85.

Reilly T, Williams AM, Nevill A, Franks A (2000) A multidisciplinary approach to talent identification in soccer. Journal of Sports Sciences 18: 695-702.

Wisloff U, Castagna C, Helgerud J, Jones R, Hoff J (2004) Strong correlation of maximal squat strength with sprint performance and vertical jump height in elite soccer players. British Journal of Sports Medicine 38: 285-288.

Wisløff U, Helgerud J, Hoff J (1998). Strength and endurance of elite soccer players. Med Sci Sports Exerc 30:462-47. 